\title{
Virginia Woolf: la política de los afectos de las «hijas de los hombres cultos»
}

\author{
Virginia Woolf: the politics of affects of the \\ «daughters of educated men»
}

ENCARNACIÓN RUIZ CALLEJÓN*

\begin{abstract}
Resumen: en las páginas siguientes abordo algunos aspectos centrales de la contribución de Virginia Woolf al pensamiento feminista: 1) Su análisis genealógico de la cultura de la violencia desde la óptica de la diferencia femenina y desde la compasión como fundamento de la ética. 2) Su transvaloración del ideal que ha regulado la vida de las mujeres en una moral y una forma de acción política contra la cultura de la violencia y que apuesta por un feminismo más allá de la igualdad.

Palabras clave: compasión, diferencia, genealogía feminista, ideal ascético, violencia.
\end{abstract}

\begin{abstract}
On the following pages I focus on some central aspects of Virginia Woolf's contribution to feminist thought: 1) Her genealogical analysis of the culture of violence from the perspective of female difference and from compassion as the foundation of ethics. 2) Her transvaloration of the ideal that has governed the lives of women in a moral and a form of political action against the culture of violence and advocates one feminism beyond equality.
\end{abstract}

Keywords: Ascetic ideal, compassion, difference, feminist genealogy, violence.

\section{1. «QQué se debe hacer, según usted, para prevenir la guerra?»}

Tres guineas ${ }^{1}$ fue escrita entre finales de 1936 y primeros del 38 y publicada en junio de ese mismo año. Fue concebida como una continuación a Una habitación propia que había aparecido en octubre de 1929. Virginia Woolf había pasado los cincuenta y era desde los años veinte una escritora consagrada: había publicado ya La señora Dalloway (1925), Al

Fecha de recepción: 29/05/2014. Fecha de aceptación: 19/11/2014.

* Universidad de Granada. Departamento de Filosofía II. Profesora Ayudante Doctora. Correo electrónico: ruizencarnacion@ugr.es. Principales ámbitos de investigación: filosofía del siglo XIX. Filosofía medieval (árabe, judía, latina). Feminismo. Crisis de valores. Entre las últimas publicaciones figuran: «Arte y religión en Schopenhauer: de la necesidad metafísica a la justificación estética de la existencia», Franciscanum: revista de las ciencias del espíritu, vol. LV, $\mathrm{n}^{\circ}$ 159, enero-junio 2013, pp. 57-103. «Naguib Mahfuz y la larga crisis del mundo árabe: escribir libros 'que hagan estremecer la tierra'», Intersticios. Filosofía. Arte. Religión, año 18, ${ }^{\circ}$ 39, 2014, pp. 53-77.

Este trabajo forma parte del Proyecto de Investigación: Las pasiones y la naturaleza humana: razón, creencias y emociones en los conflictos de valores (FFI2010-16650). Entidad financiadora: Ministerio de Ciencia e Innovación.

1 He seguido, junto con la publicación inglesa, las traducciones castellana e italiana. 
faro (1927) y Orlando (1928). Según Quentin Bell, inicialmente ella había concebido Tres guineas como un escrito menor, uno de esos proyectos más ligeros que se imponía tras una obra de envergadura, en este caso Los años. Según Jane Marcus, Tres guineas era parte de un proyecto mucho más amplio que Woolf emprendió en los años 30 pero que no llevó a cabo. Durante años recopiló materiales, ilustraciones y recortes de prensa sobre la guerra, el ascenso del fascismo, el feminismo, la relación entre la Iglesia y las mujeres, la situación de éstas en el mercado laboral o la educación femenina. Confeccionó álbumes y redactó varios cuadernos de notas que luego serían la fuente de Tres guineas, inspirarían Los años y también Profesiones para mujeres. En un principio había concebido Los años como una serie de capítulos de ficción intercalados con otros de estilo diferente, más ensayístico y basados en hechos documentados. Al final, acabó publicando la obra como una novela, aunque no estaba segura de si el experimento funcionaría ${ }^{2}$. El resto del material apareció como ensayo.

Aunque Woolf recibió numerosa correspondencia, especialmente de mujeres ${ }^{3}$, la acogida de Tres guineas fue dispar, incluso entre sus más allegados. Para algunos era poco más que un discurso panfletario y retórico, un malogrado intento de abordar el horror y la gravedad de una guerra con un asunto «menor» $\mathrm{y}$ «doméstico» ${ }^{4}$. Pero ni siquiera ese asunto salió mejor parado. Sus tesis parecían contrarias al movimiento feminista, pues había que luchar por la igualdad y esto requería movilización, visibilidad y participación política. Ya fuese desde una perspectiva u otra, el enfoque y la argumentación del texto no parecían estar a la altura de las circunstancias 5 . La propia desazón de Woolf parecía apuntar en la misma dirección de sus críticos: «...el libro que fue como una espina para mí durante todo el pasado verano; me mantuvo en el horror del último agosto; y me hizo girar como una peonza kilómetros y kilómetros por las marismas. ¿Cómo es posible que se haya diluido en tonterías disueltas? Sin embargo, sigue siendo, moralmente, una espina: lo que deseé decir, aunque fútil» ${ }^{6}$.

2 «The decision to cut 'enormous chunks' of writing from The years itself at the last minute, when it was already in gallery proofs, indicates her disquiet about the mixed project that contained 'enough powder to blow up St. Paul's '(Diary 4:77)» (Marcus, J., Introduction. Woolf, V., Three Guineas, Orlando, Harvest Book-Harcourt. Inc., 2006, p. xlv).

3 La correspondencia al respecto, 82 cartas con las respuestas de la autora, se editaron por primera vez en el Woolf Studies Annual, vol. 6 (2000).

4 Es una época en la que la propia literatura está cambiando: «un amplio e importante continente de jóvenes poetas y novelistas pedían una literatura que llevara a una acción política efectiva. Aquí quizá sea necesario recordar al lector que en 1933 -el año de publicación de Flush-Hitler llegó al poder y los japoneses asolaron Manchuria; al año siguiente, tuvo lugar lo que parecía el primer paso de una revolución fascista en Francia; en 1935, los italianos invadieron Abisinia; en 1936, empezó la guerra civil española; en 1937, los japoneses tomaron Shangai y Pekín, y en 1938 los nazis añadieron primero Austria y más tarde Bohemia y Silesia a su territorio. Mientras las fuerzas reaccionarias adquirían más y más poder, quienes se oponían a ellas tenían que considerar si la fuerza se debía contrarrestar con la fuerza. Virginia detestaba la violencia: la asociaba con las maniobras autoritarias de los varones» (Bell, Q., Virginia Woolf, Barcelona, Debolsillo, 2004, p. 536).

5 Y aún menos parecían estarlo con algo más de perspectiva: «las verdaderas críticas de Tres guineas corrieron a cargo de los acontecimientos, puesto que los acontecimientos de 1938 no centraron su atención en los derechos de la mujer sino en los derechos de las naciones» (op. cit., p. 564).

6 Cfr. En Bell, Q., op. cit., p. 563. Y también: «The reception of 3Gs. has been interesting, unexpected -only I'm not sure what I expected. 8.000 sold. Not one of my friends has mentioned it. My wide circle has widened -but I'm altogether in the dark as to the true merits of the book. Is it...? No, I wont [sic.] even formulate qualities; for, its [sic.] true, no one has yet summed it up. Much less unanimity than about Room of Ones Own» (The Diary of Virginia Woolf. Volumen five (1936-1941), San Diego, New York, London, Harvest Book, p. 193). 
Las razones que le llevaron a escribir Tres guineas responden a experiencias de distinto calado. El compromiso de la autora con la política ha sido una cuestión discutida. Se ha señalado que en absoluto estaba interesada en ella, incluso que era incapaz para la misma ${ }^{7}$. Sin embargo, participó en asociaciones, dio charlas sobre las mujeres y las profesiones, apoyó diversos proyectos y estuvo en contacto con personajes políticos. Precisamente otra forma de hacer política ${ }^{8}$ es uno de los aspectos fundamentales de Tres guineas. Quizá el detonante del ensayo fuese el encuentro con su amigo el escritor Edward Morgan Forster, quien le comunica que las mujeres no van a ser admitidas en otro nuevo comité ${ }^{\text {. La negativa }}$ hizo mella en Virginia y el libro que proyectaba, que por entonces se iba a titular On being despised ${ }^{10}$ (Cuando se nos desprecia), recibió un nuevo impulso. Estaba escribiendo Los años y es a finales del 36 cuando puede abordar el nuevo proyecto. Un factor importante fue la reflexión y la valoración de su propia educación, pues siempre tuvo muy presente la diferencia entre ésta y la recibida por sus hermanos. Y una experiencia mucho más grave y profunda fue la muerte de su sobrino Julián en la Guerra Civil Española a raíz de lo cual, en el verano de 1937, Virginia suspende su trabajo en la obra para ayudar a su hermana a recuperarse de la tragedia. En parte Tres guineas, como señala Bell, es un diálogo con Julián o con las razones que Virginia suponía que lo habían llevado a la guerra ${ }^{11}$.

7 Esa es también la opinión de Bell en la biografía citada, pero subrayando la importancia del cambio personal: «La verdadera respuesta a todo este horror y esta violencia residía en la mejora del estado moral propio; de alguna manera uno debía conseguir desterrar la ira y la sinrazón que nacen de la ira. En consecuencia tendía, de manera distinta a Leonard, a ser una pacifista a ultranza; nunca lo explicó en términos de política, pero era su reacción instintiva, lo femenino puesto a la reacción masculina, 'lo masculino bestial' » (Bell, Q., op. cit., p. 538).

8 «Neither her health nor her temperament allowed her to experience the violent demonstrations of the radical decade of feminist revolt at the beginning of the twentieth century or the equally violent antifascist demonstrations of the 1930s. Thinking was her fighting, she said (Diary 5: 285) and 'by writing, I am doing what is far more necessary than anything else' (....)» (Marcus, J., op. cit., p. xii).

«Nella sinistra inglese si moltiplicarono allore le iniziative contro il fascismo, in favore della pace e della libertà (...) Virginia, le cui simpatie andavano alla sinistra benché non fosse politicamente attiva quanto il marito Leonard Woolf, laburista fabiano, era ripetutamente invitata a partecipare. Lei era in tutto e per tutto d'accordo con gli scopi generali di quelle iniziative, ma alle richieste di partecipare rispondeva in maniera discontinua (...) Quando le capitava di aderire, ne traeva l'impressione di cose inefficaci e vuote. Era anche imbarazzata dalle sua incapacità di distinguere tra iniziative promosse da comunisti e da non comuniste, una distinzione che nel suo ambiente, di non comunisti, veniva considerata importantissima. In questi e altri casi, comunque, poteva trarsi d'impaccio consultando il marito nella cui perspicacia politica ebbe in genere fiducia» (Muraro, L., «Introduzione». En Woolf, V., Le tre ghinee, Milano, Feltrinelli, 2004, pp. 6-7).

9 «En abril de 1935, se había encontrado con E. M. Forster en la escalera de la Biblioteca de Londres, cuya Junta había discutido, según le contó, si debían admitir damas en calidad de miembros. Virginia supuso que iban a invitarla a ella, pero no lo hicieron. Después de despertar sus esperanzas, Forster se dispuso a desbaratarlas. Las damas resultaban fastidiosas, las damas eran imposibles, la Junta no quería oír hablar del asunto» (Bell, Q., op. cit., p. 544). En la introducción a la versión italiana, el encuentro con E. M. Forster, entonces comprometido en iniciativas antifascistas, se refiere a que en el comité por él propuesto las damas no serían admitidas aduciendo que en un comité las damas son una molestia. Como aclara Muraro, seguramente Forster no se refería a su amiga Virginia con la que, por otro lado, había llevado a cabo iniciativas parecidas: «Per lei faceva una implicita quanto ovvia eccezione. Virginia nondimeno fu ferita da quelle parole. Non voleva essere una eccezione tra le donne e in un certo senso non poteva esserlo, per una fragilità che il successo letterario non avveva sanato e che le impediva di abituarsi alla normale durezza dei rapporti sociali» (Muraro, L., op. cit., p. 7).

10 También proyectó como título: Answers to Correspondents.

11 Cfr. Bell, Q., op. cit., pp. 559-561. La reflexión sobre la guerra no era algo nuevo en Woolf: «Woolf had written to her friend Margaret Llewelyn Davies in 1916 that the Great War, as it was then called, was a 'preposterous 
El argumento de Tres guineas gira en torno a la respuesta de Virginia Woolf a una carta enviada tres años antes por un abogado secretario de una asociación antifascista. En la carta se pedía su colaboración para prevenir la guerra y luchar contra el avance del totalitarismo en Europa sugiriéndole de paso algunos modos de hacerlo: firmar un manifiesto comprometiéndose a proteger la cultura y la libertad intelectual, hacerse miembro de una asociación o enviar a ésta una contribución económica. Pero también se pide su opinión: «¿Qué se debe hacer, según usted, para prevenir la guerra?». Woolf empieza su respuesta justificando la tardanza: esperaba que otros tomasen la palabra o que la carta se «respondiese sola». Nada de esto ha sucedido. Y además se trata de una carta única en la historia de la correspondencia, pues ¿cuándo un hombre culto ha preguntado a una mujer cómo evitar la guerra? ${ }^{12}$. Woolf articula su respuesta, y con ello la estructura de Tres guineas, en relación a otras dos cartas también pendientes. En la segunda se pide su ayuda para una universidad donde las mujeres puedan formarse; en la tercera, para que las mujeres encuentren trabajo en sus profesiones. Al hilo de las respuestas Woolf reflexiona sobre las raíces de la violencia, la relación entre los sexos y el significado del feminismo ${ }^{13}$.

\section{El puente natural sobre el abismo que nos separa}

La respuesta a la primera carta empieza cuestionando las condiciones mismas de posibilidad del diálogo. Ciertamente el remitente y la destinataria comparten algo bien determinante en la época: pertenecen a la misma clase social. Pero Woolf apunta a una diferencia que muestra un abismo ${ }^{14}$ cuya magnitud pone en duda si vale la pena, incluso si es posible, hacerse entender por el interlocutor cuando éste es un hombre. A lo largo de la historia las mujeres no han recibido la misma educación ni han tenido el mismo acceso a la cultura. Tampoco han disfrutado de la imprescindible formación que no dan los libros ni la educación reglada ${ }^{15}$ : la que dan los viajes, los contactos sociales, las experiencias y libertad de movimientos. Tampoco han disfrutado de espacios y tiempos propios ${ }^{16}$. Esta educación robada

masculine fiction', that made her 'steadily more feminist', and in her fiction and nonfiction she began to articulate and illuminate the connections between the patriarchal status quo, the relatively subordinate position of women, and war making» (Hussey, M., «Preface». Three Guineas. Ed. Cit., pp. xiv-xv).

12 Woolf, V., Tres guineas, Barcelona, Lumen, 1999, p. 7.

13 De hecho, Tres guineas y Una habitación propia llegarán a ser textos clave del Second Wave Feminism, por ejemplo del feminismo de la diferencia. Jane Marcus presenta una visión panorámica de la influencia que aquí no puedo abordar (cfr. Marcus, J., op. cit., pp. xxxvi-xxxvii).

14 Woolf, V., Tres guineas. Ed. cit., p. 9.

15 Muy agudamente, Cristina de Pizán ya subrayaba la importancia del saber reglado: «si la costumbre fuera mandar a las niñas a la escuela y enseñarles con método, como se hace con los niños, aprenderían y entenderían las dificultades y sutilezas de todas las artes y ciencias tan bien como ellos». Pero también subrayaba la importancia de estar expuestas a influencias, experiencias, contextos diversos, vivencias: «no tienen, como los hombres, la experiencia de tantas cosas distintas, sino que se limitan a los cuidados del hogar, se quedan en casa, mientras que no hay nada tan instructivo para un ser dotado de razón como ejercitarse y experimentar con cosas variadas» (De Pizán, C., La ciudad de las damas, Madrid, Siruela, 2013, p. 77). E incluso: «mira los hombres que viven aislados en el campo o en el monte (...) son tan simples de espíritu que uno los tomaría por animales» (op. cit., pp. 77-78).

16 «Una de las cuestiones de la que era muy consciente Virginia Woolf es que para la formación de la mente del individuo moderno ha sido fundamental la privacidad. Sin privacidad, sin soledad, no son posibles ni la verdadera compañía, ni el diálogo ni la libertad. La escritora señala (...) el hecho de que la vida hogareña de las mujeres está constreñida a un espacio en el que ellas no consiguen tener privacidad. En cambio, la individualidad y la privacidad de los hombres es estimulada desde el ámbito hogareño (...) Les da a los 
ha sido sustituida por una «profesión» impuesta no retribuida: el matrimonio y la familia, cuyo desempeño es, por cierto, el pilar que sostiene y reproduce sociedades y culturas. Por extraño que parezca, las mujeres no han disfrutado de ninguno de los beneficios sociales a los que tan duramente han contribuido y han estado obligadas a perpetuar valores que no han escogido, entre ellos los de la guerra.

Esta situación es especialmente acusada en el grupo social al que la propia Virginia Woolf pertenecía y que denomina «las hijas de los hombres cultos», es decir, de los hombres que han recibido educación y ejercen profesiones liberales. Las hijas de la burguesía no disponen de las ventajas de su clase: capital y oportunidades sociales. Mientras los hombres de su clase poseen el capital, la tierra, los recursos y el poder clientelar ${ }^{17}$, ellas están condenadas a contraer matrimonio o a vivir de la caridad de los miembros masculinos de su familia ${ }^{18}$. Con fina ironía concluye Woolf que a estas mujeres, al carecer tan gravemente de formación, les es más que difícil prevenir la guerra (la pregunta de la carta), porque para dilucidar sus causas parecen imprescindibles los conocimientos que siempre les han negado. Necesitarían saber de política, de relaciones internacionales, de economía, de filosofía e incluso de teología. Las «hijas de los hombres cultos»son, pues, absolutamente incompetentes para comprender las «profundas razones» por las que se produce una guerra.

Pero es el caso que la guerra ha sido siempre un asunto humano, es decir, un asunto que depende de la voluntad de las personas ${ }^{19}$, no de causas misteriosas ni de conocimientos especializados. Más aún: la guerra ha sido y es un asunto de hombres ${ }^{20}$. La ley o la costumbre habrán desarrollado esta diferencia, «no importa si innata o accidental», especifica Woolf ${ }^{21}$. La pregunta, pues, no puede dirigirse a las mujeres. Es un problema sobre el que tienen que reflexionar y resolver los hombres ${ }^{22}$. Ellas pueden intentar comprender sus motivos mediante

hombres, según ella, además de mayor tiempo para ocupar su mente en lo que quieran, mayor seguridad y menos miedo de actuar en los espacios públicos» (García Bergua, A., «Alrededor de Virginia Woolf», Fractal, vol. V, no 17, abril-junio 2000, año 4, pp. 69-90. http://www.mxfractal.org/F17garci.html).

17 Woolf no cuestiona: qué tipo de hombre acapara las riquezas; la diferencia de clases; la redistribución de la riqueza; la desigualdad por nacimiento, etc.

18 Estos argumentos son también, no hay que olvidarlo, reflexiones sobre sí misma, la conciencia de la formación robada, de las menores oportunidades respecto a sus hermanos, de las convenciones sociales adecuadas a una dama, etc.

19 Pero también hay algo más: «Detrás de Tres guineas está presente la idea de que si uno no se concibe a sí mismo singularmente, no puede contribuir en su propio nombre a una causa, en este caso la de la paz. ¿Cómo las mujeres podían contribuir en nombre de ellas a la paz o a terminar con la guerra, si vivían en una estructura social y familiar que no les permitía actuar en su propio nombre o encontrarse a sí mismas?» (García Bergua, A., http://www.mxfractal.org/F17garci.html).

20 Cristina de Pizán afirmaba en la mima dirección: «¿Acaso son las mujeres las que comenten las atrocidades e injusticias que aquejan al mundo?» (De Pizán, C., op. cit., p. 177).

21 A este desarrollo se refiere Marcia Yudkin: «by calling war a male institution, I mean that as a matter of social and historical reality there exist structures, patterns of behavior, customs, practices, and organizations into which males, as a matter of social and historical reality, have been socialized. In our society, men have been the actual and potential perpetrators of war; men have been shaped and moulded since birth to be capable of wielding political power, of identifying their interests with those of the nationstate, of destroying life; men have been in the position to prepare for war, declare war, and wage war (Yudkin, M., «Reflections on Woolf's Three Guineas», Women Studies Int. Forum, vol 5, n 3-4, 1982, p. 263).

22 Woolf también se refiere a la matanza de animales: «la gran mayoría de los pájaros y las bestias han sido muertos por los hombres, por ustedes; y no por nosotras. Y es difícil enjuiciar lo que no compartimos» (Woolf, V., Tres guineas. Ed. cit., p. 14). Y en ese sentido, cobrará una extraordinaria relevancia, un profundo sentido, la identificación afectiva con la foto de cuerpos cuyo sexo y especie es difícil de diferenciar. 
lo que está al alcance de su formación: la lectura de biografías, autobiografías y periódicos ${ }^{23}$. $\mathrm{Y}$ estos textos apuntan al menos a tres causas que inducen a los hombres, salvo excepciones, a la guerra: la guerra es una profesión, la guerra es fuente de felicidad y diversión, y la guerra es el cauce de las cualidades viriles que de otro modo no se entrenarían y quedarían infrautilizadas. Pero estas causas son completamente extrañas a las mujeres. Y si se afirma que la razón para ir a la guerra es el patriotismo (amor al propio país) y que en este caso concreto significaría amor y lealtad a Gran Bretaña, cuna de la libertad y la democracia, también ese amor les es extraño, pues el Glorioso Imperio ha dado a las mujeres bien poco de ambas. Por tanto, las mujeres no comparten las razones, los sentimientos o las lealtades que llevan a la guerra y no pueden responder a la pregunta de la carta ${ }^{24}$. Woolf decide acudir entonces, para intentar entender las causas de la guerra, a los que «han hecho de la moralidad su profesión» ${ }^{25}$. Pero la Iglesia, pese al mensaje evangélico, no sostiene una opinión unánime. No parece entonces que pueda encontrarse algo que nos vincule a todos, un criterio moral que nos permita pronunciarnos sean cuales fueren nuestras diferencias.

Pero sobre su mesa no hay solo cartas, hay también fotografías: las que la Guerra Civil Española $^{26}$ genera puntualmente. Entre ellas, destaca la de un cuerpo tan mutilado que no es posible determinar su sexo, que incluso pudiera ser -afirma Woolf con crudeza- el de un cerdo $^{27}$. Y es al cabo de observar juntos estas fotografías de cuerpos mutilados, cuya especie y sexo es difícil de precisar, cuando vemos y valoramos, porque sentimos, lo mismo: igual rechazo y los mismos deseos de que algo así no debiera suceder. Enfrentados a estas imágenes del horror emerge una comunión natural en la que todos, hombres y mujeres, somos uno. Aparece un puente natural sobre el abismo que nos separaba. Se trata de un afecto decisivo. En este sentido, Woolf coincide con un autor como Schopenhauer que se refiere a la compasión como fundamento de la moral: «no se basa en supuestos, conceptos, religiones, dogmas, mitos, educación y cultura, (...) es originaria e inmediata, se encuentra en la misma naturaleza humana (...) y se muestra en todos los países y épocas ${ }^{28}$. Reconocemos en el que sufre a otro yo y esta experiencia de identificación se extiende además al resto de los seres vivos. Schopenhauer fue, sin embargo, un misógino. Afirmó la especial capacidad de las mujeres para la compasión, no solo porque las asociase con los valores del cuidado, sino porque la compasión en su grado fundamental es intuitiva. Sin embargo, en

23 Esta reducción, que es en principio una limitación de las mujeres, abre sin embargo una nueva perspectiva de recuperación de la memoria y de la historia de éstas. Se trata de toda la información y de todas las claves y matices presentes en otros «textos», fuera de las disciplinas. A través de esos otros textos y esas otras fuentes de información la presencia de las mujeres se hace manifiesta.

24 «La respuesta basada en nuestra experiencia y en nuestra psicología - ¿por qué luchar?- carece de valor (...) La total comprensión sólo podría conseguirse mediante una transfusión de sangre y una transfusión de recuerdos, milagro que aún no está al alcance de la ciencia» (Woolf, V., op. cit., p. 14).

25 Op.cit., p. 19.

26 «La Guerra Civil española (...) fue la primera guerra atestiguada («cubierta») en sentido moderno: por un cuerpo de fotógrafos profesionales en la línea de las acciones militares y en los pueblos bombardeados, cuya labor fue de inmediato vista en periódicos y revistas de España y el extranjero» (Sontag, S., Ante el dolor de los demás, Madrid, Santillana, 2004, p. 30).

27 Cfr. Woolf, V., op. cit., p. 20.

28 Schopenhauer, A., «Sobre el fundamento de la moral», en Los dos problemas fundamentales de la ética, Madrid, Siglo XXI, 1993, p. 237. 
su grado más alto, como justicia, requiere consolidación y un autodominio y una capacidad intelectual inalcanzable, a su juicio, para las mujeres ${ }^{29}$.

Para Woolf, es la compasión lo que precisamente la obliga a ir más allá de la emoción del momento y a emprender algo más contundente que firmar cartas, ingresar en una sociedad o contribuir a sus fondos. Se exige a sí misma pensar las raíces de esa violencia y hacer todo lo posible para extirparlas. Pero toda esta fase activa del fenómeno de la compasión es, por cierto, la que Schopenhauer niega a las mujeres. Éste olvida además que a lo largo de la historia la voluntad de una mujer ha tenido escasa o nula influencia. Incluso en la época de Woolf carece de medios para expresarse y ser eficaz: no puede firmar tratados, influir en las decisiones de Estado o predicar valores desde el púlpito. La prensa está controlada por hombres ${ }^{30}$. Ni siquiera puede empuñar las armas ${ }^{31}$. En el caso de las «hijas de los hombres con educación», su influencia es más irrisoria. Una operaria puede al menos dejar de fabricar municiones o dejar de trabajar y producir los bienes que sea. La hija de un hombre culto puede tan solo negarse a parir soldados ${ }^{32}$. Es cierto que en los salones de las aristócratas se ha hecho política y que ellas mismas han tenido influencia. Sin embargo, la influencia de su riqueza, de su rango y de su salón ha venido envuelta en otra: la de las armas de mujer, un recurso demasiado penoso y degradante, una forma de prostitución encubierta ${ }^{33}$.

La única arma de las hijas de los hombres cultos ha sido, hasta ahora, la lucha por la emancipación, que nada significa si no viene acompañada de la independencia económica. De hecho para Woolf, el auténtico cambio viene, más que por el derecho al voto ${ }^{34}$, por el acceso

29 «...las mujeres, que por la debilidad de su Razón son mucho menos capaces que los hombres de comprender los principios generales, consolidarlos y tomarlos como pauta, están por lo regular por detrás de aquéllos en la virtud de la justicia, así como en la honestidad y la escrupulosidad; por eso, la injusticia y la falsedad son sus vicios más frecuentes y la mentira su elemento propio; en cambio, superan a los hombres en la virtud de la caridad: pues el motivo de ésta es la mayoría de las veces intuitivo y habla inmediatamente a la compasión, a la que las mujeres son decididamente más sensibles. Pero sólo lo intuitivo, presente e inmediatamente real, tiene verdadera existencia para ellas: lo alejado, lo ausente, lo pasado y lo futuro, cognoscible sólo mediante conceptos, no les resulta del todo comprensible. También aquí hay, pues, compensación: la justicia es más bien la virtud masculina, la caridad más bien la femenina. El pensamiento de ver mujeres desempeñando funciones judiciales provoca risa; pero las hermanas de la caridad superan incluso a los hermanos» (Schopenhauer, A., op. cit., p. 239).

30 No puedo tratar aquí este aspecto de la crítica de Woolf, pero es muy consciente del poder de la prensa y de la construcción de la verdad. Sobre su reflexión acerca de la prensa, la formación de la opinión pública y la manipulación del patriotismo, es importante el capítulo de Judith Allen «Virginia Woolf, 'Patriotism', and 'our prostituted fact-purveyors', en Virginia Woolf and the Politics of Language. Allen compara las críticas de Woolf con obras significativas en la época: Cristianismo y patriotismo y Patriotismo y gobierno, de Tolstoi; Public Opinion, de Walter Lipmann; Propaganda, de Edward Bernays, y Falsehood in Wartime: Propaganda Lies of the First World War, de Arthur Ponsonby. Las obras de Lippman y de Ponsonby estaban en la biblioteca de Virginia y Leonard. Ella leyó a Tolstoi y escribió sobre él, ayudando más tarde incluso a la traducción de varias de sus obras para la propia Hogarth Press.

31 Una opción que ella, sin embargo, no comparte. Pero la misma crítica aparece, por ejemplo, en uno de sus textos breves: Pensamientos de paz en un ataque aéreo (Woolf, V., La muerte de la polilla y otros escritos, Madrid, Capitán Swing, 2010, p. 30).

32 Cfr. Woolf, V., Three Guineas. «Notes and References». Nota 10. Ed. cit., pp. 173-174.

33 Woolf, V., Tres guineas. Ed. Cit., p. 28.

34 Una opinión que también aparece en Una habitación propia: «De las dos cosas -el voto y el dinero-, el dinero, lo confieso, me pareció de mucho la más importante» (Woolf, V., Una habitación propia, Barcelona, Seix Barral, 2010, p. 53). 
de las mujeres a las profesiones, abiertas desde 1919. Entonces sí, cada una contará por sí misma. Podrá exponer sus ideas o disentir, y apoyar abierta y directamente cualquier causa, incluida esta contra la guerra. Ya no deberá asentir a todo por estar maniatada o para resultar un trofeo apetecible. Su influencia, y con ello su participación política, será verdaderamente desinteresada. Incluso solo entonces podrá cultivar los valores morales, aderezados antes por el egoísmo y el miedo a perder sus medios de supervivencia. Pero para desempeñar una profesión que le procure tal independencia, es indispensable adquirir la formación adecuada. Woolf imagina una nueva institución y un curriculum ideal ${ }^{35}$ que no reproduzca nuestra cultura competitiva, agresiva y deshumanizante, caldo de cultivo de los valores que fomentan la violencia. Se enseñarán, por ejemplo, las artes de la humana relación, el arte de comprender la vida y la mente del prójimo. No habrá etiqueta ni exhibición de poder, ni las servidumbres que acompañan a las insignias, a los cargos, a los trajes oficiales, etc. Las universidades no serán focos de tensión. La riqueza o la procedencia no serán relevantes. Se explorarán los medios para que el cuerpo y la mente se expresen y cooperen. Y no se crearán especialistas, sino humanistas. No se enseñarán las artes de dominar al prójimo ni de acumular capitales y tierra. El gran problema es que con este currículo para la paz y el desarrollo integral, un bonito ideal, no se irá muy lejos, porque no servirá para que las mujeres obtengan puestos de trabajo. Unos centros así concebidos tampoco atraerán la inversión. No serán viables porque no producirán los bienes que la sociedad demanda. ¿Qué hacer entonces? Si las mujeres quieren obtener un puesto de trabajo, su formación tendrá que estar en consonancia con los valores que imperan. Habrá que pactar con la realidad. Woolf pospone por ello las peticiones de la primera carta y destina su primera guinea a financiar, sin condiciones, un centro en el que las mujeres adquieran la cualificación que exige el mercado laboral. Solo de este modo se las arranca del servilismo $^{36}$ de la casa del padre y del domicilio conyugal y se evita que toda su influencia acabe apoyando, de uno u otro modo, los valores que llevan a la guerra.

La tercera carta que espera respuesta solicita la ayuda de la autora para que las hijas de la burguesía encuentren un trabajo. Sorprende que los discursos y las publicaciones oficiales de la época afirmen que la igualdad es un hecho y que las profesiones están abiertas a todos sin distinción. Pero aplicando unas «lentes más potentes», aparece ante nuestros ojos un paisaje bien distinto. El patriarcado, afirma Woolf, sigue siendo una hacienda muy floreciente. Aparte del nepotismo y el favoritismo, las mujeres que buscan trabajo deben vencer la discriminación en razón de su sexo. Y aún consiguiéndolo, solo alcanzarán puestos de escasa relevancia ${ }^{37}$. Por

35 Un curriculum en el que, paradójicamente, no hay ninguna materia sobre la historia y el pensamiento de las mujeres. Woolf privilegia materias relativas al entendimiento, a la comprensión del otro y al desarrollo integral de los individuos.

36 Un servilismo del que también habla al hacer balance de cómo cambia la situación de una mujer que tiene independencia económica: «No necesito odiar a ningún hombre; no puede herirme. No necesito halagar a ningún hombre; no tiene nada que darme. De modo que, imperceptiblemente, fui adoptando una nueva actitud hacia la otra mitad de la especie humana (...) Tenían, es cierto, dinero y poder, pero sólo a cambio de albergar en su seno un águila, un buitre que eternamente les mordía el hígado y les picoteaba los pulmones: el instinto de posesión, el frenesí de adquisición, que les empujaba a desear perpetuamente (...) Al ir dándome cuenta de estos escollos, el temor y la amargura se fueron transformando poco a poco en piedad y tolerancia; y luego (...) llegó la mayor liberación de todas, la libertad de pensar directamente en las cosas» (Woolf, V., Una habitación propia. Ed. Cit., pp. 54-55).

37 «Esa distinción de sexo parece poseer cierta curiosa calidad de plomo que mantiene a todo nombre al que la distinción va unida en las más bajas esferas» (Woolf, V., Tres guineas. Ed. cit., p. 88). 
eso Woolf dona su segunda guinea a la tesorera de esta asociación para que ayude a las hijas de la burguesía a encontrar trabajo. Solo así tiene sentido plantear la influencia real de éstas y su capacidad para prevenir la guerra. Se trata de una cadena de causas interdependientes.

\section{Del velo de San Pablo al desfile con los hombres con educación}

Hemos llevado ropas específicas durante todo este tiempo, sobre todo el velo que San Pablo exigía en la Carta a los Corintios $^{38}$, pero pronto luciremos otras: las de la vida pública, las de las profesiones. Estamos en el puente por el que desfilaban los hombres con educación, si bien aún a la zaga y «trotando», sin tener un paso propio. Hemos de preguntarnos -aquí, ahora, sobre la marcha- si queremos unirnos al desfile de los hijos de los hombres cultos, al tropel del mundo de nuestros hermanos y a la parafernalia de las profesiones, con sus ceremonias, insignias, lealtades y servilismos. Todo ello es el caldo de cultivo de los valores que fomentan la competitividad, el egoísmo, el sectarismo y, en último término, la cultura de la guerra. Lograda la independencia económica, nos encontramos ante un nuevo peligro que Woolf identifica con el último tentáculo del sistema patriarcal: pasar de ser víctimas del patriarcado a paladines del capitalismo. Los valores que imperan en las profesiones, tal y como se vienen desempeñando, son creados por los hombres y exigen el sacrificio de la vida personal y renovadas servidumbres. Aunque el valor dinerario de la vida profesional es grande, Woolf cuestiona su «valor espiritual, moral e intelectual», pues quienes tienen gran éxito en el ejercicio de su profesión «pierden los sentidos». ¿Qué significa esto?: «Se quedan sin visión. No tienen tiempo para mirar cuadros. Se quedan sin sonido. No tienen tiempo para escuchar música. Se quedan sin habla. No tienen tiempo para conversar. Se quedan sin el sentido de la proporción, de las relaciones entre las cosas. Se quedan sin humanidad. Ganar dinero llega a ser tan importante que deben trabajar por la noche igual que de día (...) ¿Qué queda, pues, en el ser humano que ha perdido la visión, el sonido y el sentido de la proporción? Solo un tullido en una caverna ${ }^{39}$.

Nos encontramos entre dos males: «a nuestra espalda, tenemos el sistema patriarcal; el hogar, con su inanidad, su inmoralidad, su hipocresía, su servilismo. Ante nosotras, tenemos el mundo de la vida pública, el sistema profesional, con su carácter absorbente, sus celos, su

38 «Quiero que sepáis que la cabeza de todo hombre es Cristo; y la cabeza de la mujer es el hombre; y la cabeza de Cristo es Dios. (...) Y toda mujer que ora o profetiza con la cabeza descubierta, afrenta a su cabeza; es como si estuviera rapada. Por tanto, si una mujer no se cubre la cabeza, que se corte el pelo. Y si es afrentoso para una mujer cortarse el pelo o raparse, ¡que se cubra! El varón no debe cubrirse, pues es imagen de la gloria de Dios; pero la mujer es gloria del varón. En efecto, no procede el varón de la mujer, sino la mujer del varón. Ni fue creado el varón por razón de la mujer, sino la mujer por razón del varón. He ahí por qué debe llevar la mujer sobre la cabeza una señal de sujeción por razón de los ángeles. Por lo demás, ni la mujer sin el varón, ni el varón sin la mujer, en el Señor. Porque si la mujer procede del varón, el varón, a su vez, nace mediante la mujer, y todo proviene de Dios. Juzgad por vosotros mismos (...) ¿No os enseña la misma naturaleza que es una afrenta para el varón la cabellera, mientras que es una gloria para la mujer la cabellera? En efecto, la cabellera le ha sido dada a modo de velo. De todos modos, si alguien quiere discutir, no es ésa nuestra costumbre ni la de las iglesias de Dios» (1 Cor. 11. 2-16). La orden de Pablo, evidentemente, vendría seguida de muchas otras. Virginia Woolf también se refiere a la posición de la Iglesia sobre los deseos de las mujeres de recibir educación: «Cuando pensamos en el criterio de la Iglesia sobre este tema, criterio que, según nos dicen las biografías, imperaba todavía hace pocos años- «...y me fue dicho que el deseo de aprender en las mujeres era contrario a la voluntad de Dios...»» (Woolf, V., Tres guineas. Ed. cit., p. 46).

39 Op.cit., p. 126. 
competitividad, su codicia ${ }^{40}$. En el mundo profesional impera la seducción de la posesión y los privilegios; la atrofia de la autocrítica y la legitimación a toda costa del poder económico, social, cultural. Todas estas son condiciones que favorecen la deshumanización y la cultura de la violencia. Por eso Woolf constata en el feminismo de la igualdad cierta miopía. Reconociendo que ha cumplido una función absolutamente necesaria y sin afirmar por ello que deba ser enterrado como una reliquia del pasado, aunque también sin pronunciarse sobre su situación fuera del ámbito occidental, considera que es insuficiente. Puede ser nefasto si las mujeres aspiran solo a ser como los hombres, si confunden sus objetivos y su libertad con la nivelación, si adoptan como medida la medida de otros, si reproducen los valores que precisamente pretendían abolir. Es imprescindible una genealogía de los valores desde la perspectiva de género, el análisis de las motivaciones en todos los productos culturales. Por eso Woolf afirma que la hija del hombre con educación está obligada a «despojar todas las manifestaciones de su motivación dineraria, de su motivación de anuncio, de su motivación de publicidad, de su motivación de vanidad y de todas las restantes motivaciones (...) antes de decidir» ${ }^{41}$. La esfera privada y la pública no están separadas. Será nuestra ruina si usted olvida la figura privada y nosotros olvidamos el mundo público, avisa Woolf al final de su larguísima carta. No podemos tampoco disociarnos de la figura de la foto, somos esa figura. Toda la carta de Woolf es un esfuerzo por estar a la altura de una fotografía que diluye el resentimiento y descubre un puente que ha estado siempre allí. Woolf propone una política de mujeres fundada en valores como la compasión, el pacifismo y la solidaridad. Hoy, además, hay que hacer justicia a viejas y nuevas fotos; a fotos de otras culturas, incluso a fotos que no son de nuestra especie. Pero no ha cambiado la exigencia de cultivar siempre de nuevo aquel sentimiento, entre otras cosas porque el exceso de imágenes, la sobreexposición a un afecto, acaba por inmunizarnos.

\section{La larva del dictador y el espíritu del sacerdote}

Por otra parte, la lucha contra el totalitarismo y la defensa de la democracia que se exigen en la primera carta no es distinta a la lucha que han venido sosteniendo las llamadas «feministas». El movimiento de las mujeres ha sido la vanguardia. Sus objetivos no han sido solo los derechos de la mujer, ni solo las libertades públicas. El estado patriarcal y el estado fascista en realidad son uno para Woolf, porque ambos legitiman y ejercen la violencia de una parte de la humanidad hacia otra. Un dictador ${ }^{42}$ impone a sus semejantes el modo en que han de vivir, incluso cómo deben ser y sentir. Da igual que se apoye en Dios, la naturaleza, el sexo o la raza. Por eso, la discriminación y la violencia de género son un síntoma de un fenómeno mucho más profundo y peligroso: «algo que, si se difunde, puede envenenar por igual a ambos sexos (...) El huevo de este mismo gusano que conocemos, bajo otros nombres, en otros países. En embrión, tenemos ahí a ese ser, el dictador (...) Y está aquí, entre nosotros, alzando su repulsiva cabeza, escupiendo su veneno, todavía pequeño (...) pero en

40 Op.cit., p. 129.

41 Op.cit., p. 171.

42 En Pensamientos de paz en un ataque aéreo, en palabras de Lady Astor, Woolf alude al «hitlerismo subconsciente en el corazón de los hombres (...) es el deseo de agresión, el deseo de dominar y esclavizar (...) Si pudiéramos liberarnos de la esclavitud, deberíamos liberar a los hombres de la tiranía. Los Hitler son criados por esclavos» (op. cit., p. 32). 
el corazón de Inglaterra. ¿Y la mujer que tiene que respirar esta ponzoña y luchar contra este insecto, en secreto y sin armas, (...) acaso no lucha contra los fascistas y los nazis, lo mismo que quienes luchan con ellos, con las armas, bajo los focos de la publicidad? (...) ¿Es que no tenemos que ayudarla a aplastar a este dictador en nuestro país, antes de pedirle que nos ayude a aplastarlo en el exterior? ¿Y qué derecho tenemos, señor, a vocear nuestros ideales de libertad y de justicia en otros países, cuando, pudiendo sacudir (...) un huevo como éste no lo hacemos? $\gg^{43}$. En la guerra que se libra en Europa el monstruo ha salido por completo a la superficie y ya no solo envenena las relaciones entre los sexos: «Ahora ustedes sienten, en su propia persona lo que sintieron sus madres cuando se las encerraba y se las hacía callar, por ser mujeres. Ahora a ustedes se les encierra y se les hace callar porque son judíos, porque son demócratas, por su raza, por su religión (...) Ahora las cosas les parecen diferentes» ${ }^{44}$.

Woolf dona, sin embargo, su tercera guinea, respondiendo a la petición de la primera carta. Pero es fundamental el momento y el modo. Ha apoyado primero los proyectos para mujeres y dona esta guinea para defender la libertad de todos, hombres y mujeres, y lo hace desde una posición especialmente desinteresada: «Es una donación libre, dada sin miedo, sin ánimo de halago y sin condiciones» ${ }^{45}$. Y rechaza formar parte de la asociación que le sugiere el tesorero: «Supongamos que el duque de Devonshire, con su estrella y su liga, entrara en la cocina y le preguntara a la criada dedicada a pelar patatas (...): «Deje de pelar patatas, Mary, y ayúdeme a estructurar cierto párrafo un tanto difícil, debido a Píndaro»» ${ }^{46}$. La escena es ridícula e insultante, como la petición del tesorero que solicita ayuda a alguien que, por ser mujer, cuenta cero en la sociedad y es considerada una eterna menor de edad a la que la educación le ha sido siempre negada.

La educación, un valor supremo, ha sido incapaz de crear una cultura de la paz y ha segregado a media humanidad. A esta mitad se le ha administrado una pseudo-educación destructiva. En este sentido creo que es importante traer a colación algunos aspectos del análisis nietzscheano al respecto. La educación de la humanidad ha estado dirigida por «la imaginación extravagante de carceleros y verdugos» ${ }^{47}$, sostiene Nietzsche en Aurora. Y en el Crepúsculo de los ídolos se refiere al educador más importante de Occidente y a la técnica educativa por excelencia: al sacerdote y a la doma ${ }^{48}$. El sacerdote al que Nietzsche se refiere en La genealogía de la moral es un tipo humano, un estado y una forma de estar en la realidad, y con ello un mecanismo psicológico y una técnica de manipulación para imponer un ideal concreto. Nietzsche ejemplifica el surgimiento del sacerdote como una escisión dentro de un estrato social natural: los nobles. Los nobles son los que tienen el poder, pero muy especialmente y como consecuencia, los que se sienten anímicamente superiores y especialmente seguros de sí mismos, autosatisfechos. De ahí que sus valoraciones y acciones sean un reflejo de sí mismos y de su estado. En principio, el sacerdote era tan solo el descontento con la situación que le

43 Woolf, V., Tres guineas. Ed. cit., pp. 97-98.

44 Op.cit., pp. 181-182.

45 Op. cit., p. 179.

46 Op. cit., p. 153.

47 Nietzsche, F., Aurora. Pensamientos sobre los prejuicios morales. Libro primero, § 13, Madrid, Biblioteca Nueva, 2000, p. 70.

48 Nietzsche, F., Crepúsculo de los ídolos o Cómo se filosofa con el martillo. «Los «mejoradores» de la humanidad», § 2, Madrid, Alianza, 1993, p. 72. 
ha tocado vivir, una situación que no se excluye sea dura, opresiva, cruel. Pero es sobre todo el descontento consigo mismo, el que carece de la determinación suficiente para actuar en la dirección deseada. Es incapaz de partir de sí, de aceptarse, expresarse y exponerse. Su malestar y su angustia, consigo mismo y con su suerte, pronto son autoengaño y una valoración que falsea su situación, y que se expresa como resentimiento contra lo diferente o contra lo que no consigue dominar. Se consume en la reacción y en la victimización. Racionaliza entonces sus afectos y difama lo que desea, lo que teme, lo que desconoce, lo que quiere controlar. Y todo esto del único modo que aún tiene a su alcance: manipulando simbólicamente, redefiniendo y renombrando afectos. La estrategia consiste en separar al otro de lo que puede mediante un proceso de reinterpretación de los valores ${ }^{49}$ utilizando la legitimación religiosa y la sanción moral $^{50}$. Sus propios valores los presenta como la Verdad, una verdad que solo él conoce. Pero entonces ya no es solo un resentido, sino un «sacerdote» ansioso de un rebaño al que únicamente él dirige, reconforta y redime. La sumisión deseada y la victoria sobre los fuertes, que en principio fueron capaces de asimilar su paso del animal al hombre -el malestar de la cultura-, quedan garantizadas para siempre. El dominio simbólico, el viejo recurso del hombre mítico frente a la divinidad y las fuerzas de la naturaleza es ahora un potente mecanismo de manipulación. En un fragmento del otoño de 1887 Nietzsche escribe: «la condena moral como medio de poder. A. 'excitar la mala conciencia' para que se vuelvan necesarios los salvadores, sacerdotes y similares, o bien: B. excitar la buena conciencia: para poder tratar a sus adversarios como malos y abatirlos» ${ }^{51}$. La transvaloración del sacerdote y el instinto de rebaño dominan entonces con la violencia de una «idea fija» y de una «enfermedad mental».

El sacerdote ascético despliega sus estrategias especialmente entre individuos sufrientes, es decir, de los estratos inferiores, con esclavos o con prisioneros, o con mujeres, las cuales son en la mayoría de los casos, dice Nietzsche, ambas cosas: esclavas y prisioneras. Y es aquí donde es posible un diálogo entre Woolf y de Nietzsche, no solamente porque ambos utilizan el método genealógico, sino porque ambos identifican la misma patología y la misma estrategia de manipulación. Y remiten a un mismo problema de fondo: la incapacidad para construir un universo propio sin aplastar el de los otros, la necesidad de dominar para establecer la propia identidad ${ }^{52}$. En el caso de Woolf, se apunta a un problema de identidad masculino, pero en un sentido distinto al que insinúa Nietzsche cuando señala la divergencia entre los ideales del hombre guerrero y los del contemplativo en términos de impotencia, de falta de virilidad. Para Woolf, la escisión y la patología primordial no es la que acontece dentro de la clase de los nobles. El abismo del que habla no es una cuestión de clases ni de marcas biológicas. ¿Cómo podría determinarnos tanto la biología? Woolf estaba al tanto de las reflexiones que iban apareciendo sobre los sexos en psicología. En

49 «El juicio y la condena morales constituyen la venganza favorita de los hombres espirituales limitados contra quienes no lo son tanto, y también una especie de compensación por el hecho de haber sido mal dotados por la naturaleza, y, en fin, una ocasión de adquirir espíritu y volverse sutiles» (Nietzsche, F., Más allá del bien y del mal. Preludio de una filosofía del futuro. Sección séptima: «Nuestras virtudes», § 219, Madrid, Alianza, p. 164).

50 No en vano habla Nietzsche de la moral como «consecuencia, como síntoma, como máscara», pero también «como enfermedad, como malentendido (...) como causa, como medicina, como estímulo, como freno, como veneno» (Nietzsche, F., La genealogía de la moral. «Prólogo», § 6, Madrid, Alianza, 1987, p. 23.

51 Nietzsche, F., Fragmentos póstumos (1885-1889). Vol. IV, Madrid, Tecnos, 2008, p. 274.

52 El hombre, había dicho Schopenhauer, «quiere disfrutar todo, tener todo, pero, puesto que eso es imposible, quiere al menos dominarlo todo» (Schopenhauer, A., op. cit., p. 222). 
1924 la Hogarth Press de los Woolf se convirtió en la editorial oficial para la publicación de las obras de Freud al inglés. En Tres guineas se refiere a cómo la psicología denomina esta patología primordial, masculina, una «fijación infantil». Ella prefiere un término desprovisto de una teoría científica, pero bien fundado en la experiencia y la historia: germen $^{53}$. Rechaza unirse a la psicología del XIX que presupone la inferioridad de las mujeres y de las minorías étnicas. Para Woolf el problema de fondo está claro: el dominio exige sumisión. La satisfacción de quien domina responde a una necesidad enfermiza. Sirve al resentido para construir su identidad, para afirmarse. Se trata de una identidad que no se construye ni partiendo de sí ni en el intercambio con otros. No es autónoma ni activa, sino reactiva. «Sacerdote» es aquí quien experimenta la presencia de la mujer como una amenaza que cuestiona su propio ser, su identidad. La tesis aparecía ya en Una habitación propia: «Sin duda tenía la culpa la campaña de las sufragistas. Debía de haber despertado en los hombres un extraordinario deseo de autoafirmación; debía de haberles empujado a hacer resaltar su propio sexo y sus características (...) Y cuando uno se siente desafiado (...) reacciona, si no le han desafiado antes, un poco demasiado fuerte» ${ }^{54}$. Para defenderse y autoafirmarse se recurre a la violencia simbólica, a la imposición de interpretaciones y a todas las racionalizaciones posibles, especialmente mediante la moral, la religión, la ciencia, la ley. Lo importante es que todo ello «demuestre», legitime, la inferioridad y asegure un modelo femenino único, estático, controlable. Y con este modelo, no con personas de carne y hueso, es con el que hay que relacionarse. El hombre ha sido para la mujer el sacerdote del que habla Nietzsche en La genealogía.

San Pablo consagra definitivamente el abismo con la mujer velada y sometida, pero la religión o la moral no son la causa última. Woolf señala en la misma dirección que Nietzsche. Para ambos, la religión y la moral son grandes medios, los medios por excelencia, que además se van retroalimentando de esta patología. Por eso Woolf afirma que escribir «desarme» en una mesa de negociaciones no es suficiente. El soldado puede dejar de ser soldado, pero no puede abandonar, sin más, la tradición y la educación, los valores viriles, en los que ha sido educado ${ }^{55}$. No deja de ser inquietante que ambos autores apunten hacia un desequilibrio, una patología, que atraviesa la historia y se repite. ¿Puede ser sólo la envidia la explicación de toda la historia del patriarcado, o lo que es lo mismo, de la historia de la humanidad? ¿O lo es cierta voluntad de poder unida al miedo, a la inseguridad, a sentirse amenazado? La desazón de Woolf, la zona pantanosa a la que hace referencia y que mencioné al principio, parece tener su razón última aquí: donde esperaba encontrar importantes causas con las que explicar la cultura de la violencia y clarificar la relación entre los sexos, encuentra el miedo,

53 Pero también lo llama «huevo», el huevo de ese monstruo, el dictador. No estamos instruidas, no tenemos un nombre científico para este fenómeno, pero podemos detectarlo, podemos olerlo: «Nosotras, que no somos científicas, le hemos dado un nombre erróneo. Le hemos llamado huevo, germen. Lo olimos en la atmósfera; percibimos su presencia en Whitehall, en las universidades, en la Iglesia» (Woolf, V., Tres guineas. Ed. Cit., p. 221).

54 Woolf, V., Una habitación propia. Ed. Cit., p. 134.

55 «debemos ayudar a los jóvenes ingleses a erradicar en su interior el amor por las medallas y las condecoraciones. Hemos de crear más actividades honrosas para aquellos que tratan de superar su instinto de lucha, su hitlerismo subconsciente. Debemos compensar al hombre por la pérdida de su arma (...) Debemos permitirle el acceso a los sentimientos creativos (...) Debemos liberarlo de la máquina (...) Pero ¿qué sentido tiene liberar al joven inglés si el joven alemán y el joven italiano siguen siendo esclavos?» (Woolf, V., Pensamientos de paz en un ataque aéreo. Ed. Cit., pp. 34-35). 
la ignorancia, la inseguridad, la envidia. En Una habitación propia afirma: «este interesante y oscuro complejo masculino que ha tenido tanta influencia sobre el movimiento feminista; este deseo profundamente arraigado en el hombre no tanto de que ella sea inferior, sino más bien de ser él superior, este complejo (...) $\gg^{56}$. Donde se esperaba encontrar el Mal, con mayúsculas, inasible, misterioso, tan sólo aparece lo humano, demasiado humano.

\section{El ideal ascético, la «extraña» y la muerte del «Ángel de la casa»}

El abismo que señala Woolf ha alimentado un sentimiento de culpabilidad que desautoriza a las mujeres ante sí mismas. Ha impedido a la humanidad ser libre en sus relaciones. Y ha revertido también en sus artífices, los hombres, al imponerles una imagen de la virilidad que también los aplasta como individuos. En el Tercer tratado de La genealogía de la moral Nietzsche se refiere al ideal ascético como el único modelo que hasta ahora ha seguido la humanidad, un ideal ambivalente que puede ser instrumentalizado por tipos humanos diversos, por distintas políticas de los afectos, porque de eso se trata en el fondo. Por ejemplo: entre mujeres «significa en el mejor de los casos, un amabilidad más de la seducción, un poco de morbidezza sobre la carne hermosa, la angelicidad de un bello animal grueso (...) $\gg^{57}$. $\mathrm{Y}$ entre mujeres enfermas, en el sentido en que Nietzsche utiliza «enfermo» en La genealogía, es un medio para «dominar, oprimir, tiranizar» ${ }^{58}$. Para Nietzsche, la superación del ideal ascético, el ideal educativo hasta ahora existente, ha de inspirarse en el ideal griego trágico porque éste afirmaba y celebraba la vida, la finitud, lo humano. Para Woolf, la urgencia es otra: la liberación económica y social de las mujeres. Y no tiene sentido ninguna inspiración de ese tipo: la mujer griega vivía en el patriarcado.

Sin embargo, en Tres guineas está presente el ideal ascético. Nadie como las mujeres para hablar con autoridad del tema, ellas que han sido sistemáticamente domadas tan en profundidad por sus valores. Pero Woolf expresa otra relación de las mujeres con este ideal. La educación robada y la profesión impuesta es cierto que han modelado mentes y cuerpos, y han creado una diferencia de la que surge una realidad emocional distinta. Miramos lo mismo, la misma realidad, pero la vemos de modo diferente ${ }^{59}$. Una perspectiva y una forma de vida basada en una tradición y una educación forzadamente distintas. Por eso el valor de la ayuda de las mujeres, en este caso contra la guerra, radicará necesariamente en las potencialidades de esa diferencia. Somos distintas, afirma siempre de nuevo Woolf, pero se niega a explicar esto con teorías biológicas u otras por el estilo y rechaza el esencialismo. Sencillamente hemos sido representadas distintas, obligadas a asumir una identidad cuya autoría no nos pertenece.

Woolf propone, sin embargo, partir del ideal ascético y de sus valores. En esta aceptación de las virtudes ascéticas ${ }^{60}$ no se hace de la necesidad virtud. Aquí hay algo del amor

56 Woolf, V., Una habitación propia. Ed. cit., p. 77.

57 Nietzsche, F., La genealogía de la moral. Tratado tercero: «QQué significan los ideales ascéticos?», § 1. Ed. cit., p. 113.

58 Cfr. Loc. Cit., § 14, p. 144.

59 «De lo cual parece seguir el indiscutible hecho de que «nosotras» - y este «nosotras» significa una unidad integrada por cuerpo, cerebro y espíritu, sometida a la influencia del recuerdo y las tradiciones- forzosamente seguimos siendo diferentes de «vosotros» (...). Pese a que vemos un mismo mundo, lo vemos con ojos diferentes» (Woolf, V., Tres guineas. Ed. cit., p. 33).

60 En su época: victorianas, como ella misma añade. 
fati de Nietzsche ${ }^{61}$. Partir además del ideal ascético tiene la ventaja de hacer pie en un ideal efectivamente existente. Y lo más importante: aquellas «esclavas y prisioneras» no lo han perpetuado siempre y, sobre todo, no han cultivando el resentimiento ni han caído en la victimización. Han llevado a cabo su propia transvaloración. Esto significa al menos que en sus luchas las mujeres han reivindicado libertad para todos y también que ellas son, respecto a la superación del ideal ascético, un ejemplo que Nietzsche pasó por alto. Si a las virtudes del ideal ascético ahora podemos añadirles -afirma Woolf- un poco de poder económico y de formación y la capacidad para dedicarse a causas reales, sería posible desempeñar las profesiones liberales con un mínimo de seguridad e intentar un nuevo orden simbólico. «Pobreza» significaría entonces dinero suficiente para vivir, para no depender de otro ser humano, pero ni un céntimo más. «Castidad» significaría no castidad del cuerpo, sino de la mente ${ }^{62}$, para que nos resistamos a vender nuestros cerebros por dinero, títulos, poder, reconocimiento. No menos importante es la libertad respecto a las ficticias lealtades que crean el amor a la patria, las convicciones religiosas o los grandes ideales en los que no se nos ha dejado participar.

También hay una importante similitud entre el «espíritu fuerte» de La genealogía y la «extraña» de Tres guineas. Ninguno de los dos autores rechaza la importancia de la mediación con los demás, todo lo contrario, pero ambos proponen un necesario paso previo: partir de sí, un sano egoísmo ${ }^{63}$. Woolf rechaza referirse a las mujeres como grupo homogéneo y rechaza las etiquetas. Lo que para la sociedad es inferioridad, retraso, inadecuación, Woolf lo reconoce como cancelación de la diversidad ${ }^{64}$. Hay que quemar incluso la palabra «feminismo», nos dice. Rechaza la participación en los circuitos sociales, pues si nos unimos a ellos repetiremos sus errores, nos perderemos en los ideales androcéntricos, cancelando y ahogando la perspectiva y la experiencia que las mujeres han acumulado sobre la sociedad y el mundo ${ }^{65}$, una experiencia de oprimidos y exiliados que es un valioso espejo crítico y reflexivo. Por esta razón, cuando dona su tercera guinea especifica: «La donante no le pide que la admita usted en el sacerdocio (...), o en la Bolsa, o en el Servicio Diplomático. La donante no desea ser «inglesa» en la misma medida que usted es «inglés». La donante no desea ser admitida, a

61 «Quiero aprender cada vez más a ver la belleza existente en la necesidad de las cosas -así yo seré uno de los que las embellezcan. Amor fati: ¡que éste sea mi amor a partir de ahora! (...) No pretendo acusar, ni siquiera acusar al que acusa. ¡Que apartar la vista sea mi única negación! Y, para decirlo todo y de golpe, ¡quiero ser algún día alguien que sólo sepa decir sí!» (Nietzsche, F., La ciencia jovial [La gaya scienza]. Libro IV, § 276, Madrid, Biblioteca Nueva, 2001, p. 266.

62 Se trata de evitar el adulterio con el cerebro. Woolf se refiere al significado del verbo «adulterar»: «significa, según el diccionario, falsificar mediante la mezcla de ingredientes de menor valor. El dinero no es el único ingrediente de menor valor. La notoriedad y la publicidad también adulteran» (Woolf, V., Tres guineas. Ed. cit., p. 167). En Una habitación propia afirma: «La castidad tenía entonces, sigue teniendo hoy día, una importancia religiosa en la vida de una mujer y se ha envuelto de tal modo de nervios e instintos que para liberarla y sacarla a la luz se requiere un coraje muy poco corriente (...) Un residuo del sentido de castidad es lo que dictó la anonimidad a las mujeres hasta fecha muy tardía del siglo diecinueve» (op. cit., p. 70).

63 Se trata de dos formas de sano egoísmo. En el caso de Woolf es claro este «partir de sí». Nietzsche se refiere al cultivo del egoísmo, a la escultura de sí del espíritu fuerte o libre.

64 Cfr. Muraro, L., op. cit., p. 13.

65 «For by so doing we should merge our identity in yours (...) We should not give effect to a view which our own experience of 'society' should have helped us to envisage» (Woolf, V., Three Guineas. Ed. Cit., p. 125). La edición castellana omite esta afirmación presente también en la edición italiana: «Perché così facendo annegheremo la nostra identità nella vostra» (Woolf, V., Le tre ghinee. Ed. cit., p. 143). 
cambio de la donación, en profesión alguna; no quiere honores, títulos ni medallas; no quiere cátedras; no quiere ser miembro de sociedades, comisiones ni juntas» ${ }^{66}$.

Con la «Sociedad de las Extrañas», Woolf sostiene una política de no-intervención de las mujeres, un feminismo ciertamente intempestivo en la época. Se trata de una «sociedad» sin organización, sin miembros, ideario, estatutos o sede, sin honores, jerarquías y ceremonias. Esta sociedad no participa en el juego de la política tradicional. En vistas a lo que ha hecho la patria (cualquier patria) por las mujeres, la extraña proclama: «en mi condición de mujer, no tengo patria (...) Mi patria es el mundo entero» ${ }^{67}$. Se practica la disidencia, la ausencia y la indiferencia respecto a la sociedad androcéntrica, pero con la vista puesta en la construcción de fines comunes e irrenunciables (justicia, igualdad y libertad para todos). En realidad esta ha sido la praxis efectiva de tantas mujeres a lo largo de la historia. Esta «sociedad» no es esclava de lealtades ni depende de motivos interesados, lo que permite autonomía y experimentación. Se critica y cuestiona. Se desvelan las motivaciones de ideales, valores, instituciones, pero también se han de crear nuevos valores. La «extraña» o «disidente», o la imaginada poetisa hermana de Shakespeare, y el «espíritu fuerte» de $L a$ genealogía han utilizado el ideal ascético como medio ${ }^{68}$, y comparten ahora un mismo programa de «no-intervención», si bien desde cada lado del abismo. Es necesaria la voluntad de desierto ${ }^{69}$ de la que habla Nietzsche, de cómo -en este caso el filósofo- se recata de la luz demasiado intensa, de su época y del hoy, hace escaso uso de las grandes palabras, no quiere ser mártir de la Verdad y su divisa es «quien posee es poseído» ${ }^{70}$. Esta no-intervención no es inactividad. Es compatible con la posición que defiende, entre otras, Marcia Yudkin: «Why not instead put on the uniform and laugh or scowl but don't believe in it, and use the privilege of our positions to engender a world of peace, with equality instead of hierarchy, leadership instead of domination, self-mastery instead of mastery over others, cooperation instead of competition, skills and talents used to draw people together rather than to wedge them apart? ${ }^{71}$. La imaginada poetisa hermana de Shakespeare es también la contrapartida del modelo del superhombre, pero apunta a la reconciliación, a la unión de la humanidad, a la vez que al respeto de las diferencias. La imaginada poetisa ya libre materialmente lo es también intelectualmente. Acostumbrada a la libertad, escribe exactamente lo que piensa, evadida de la «sala de estar común ${ }^{72}$ y con una nueva perspectiva: ve a los seres humanos

66 Woolf, V., Tres guineas. Ed. cit., p. 179.

67 Op.cit., p. 192.

68 «como condiciones más propias y más naturales de su existencia óptima» (Nietzsche, F., La genealogía de la moral. «Tercer tratado», $§ 8$. Ed. cit., p. 126).

69 «Y lo seguro es que ninguno de los comediantes del espíritu resistió en absoluto en él, -ipara ellos no es bastante romántico, bastante sirio, no es bastante desierto de teatro! De todos modos, tampoco en él faltan camellos: pero a esto se reduce toda su semejanza. Una oscuridad arbitraria, tal vez; un evitarse a sí mismo; una esquivez frente al ruido, la veneración, el periódico, la influencia; un pequeño oficio, una vida corriente, algo que, más bien que sacar a la luz, oculte; (...) y aun a veces un cuarto en una fonda abierta a todo el mundo, abarrotada, en la que uno está seguro de ser confundido con otro y en la que puede hablar impunemente con cualquiera, - esto es aquí 'desierto' (...) Aquello de lo que Heráclito huía continúa siendo lo mismo de lo que nos apartamos nosotros ahora: el ruido y la charlatanería de demócratas de los efesios, su política, su chismorrería del 'hoy', -pues nosotros los filósofos necesitamos sobre todo calma de una cosa: de todo 'hoy'» (loc. cit., p. 127).

70 Loc. cit., p.128.

71 Marcia Yodkin, op. cit., p. 268.

72 Woolf, V., Una habitación propia. Ed. Cit., p. 153. 
«no siempre desde el punto de vista de su relación entre ellos, sino de su relación con la realidad» ${ }^{73}$; ve «el cielo, y los árboles, o lo que sea, en sí mismos» ${ }^{74}$; está relacionada «con el mundo de la realidad y no sólo con el mundo de los hombres y las mujeres» ${ }^{75}$.

Esta nueva perspectiva permite otras relaciones y valoraciones: «a sus ojos, los hombres habían dejado de ser la «facción de la oposición»; no necesitaba perder tiempo prorrumpiendo en invectivas contra ellos (...). El temor y el odio habían casi desaparecido (...) Escribía como mujer, pero como una mujer que ha olvidado que es una mujer, de modo que sus páginas estaban llenas de esa curiosa cualidad sexual que sólo se logra cuando el sexo es inconsciente de sí mismo» ${ }^{76}$. Quizá sea éste el sentido profundo de la apuesta de Virginia por la androginia: «la mente andrógina es sonora y porosa; (...) transmite la emoción sin obstáculos; (...) es creadora por naturaleza, incandescente e indivisa (...) Y si es cierto que el no pensar especialmente o separadamente en la sexualidad es una de las características de la mente desarrollada, cuesta ahora muchísimo más que antes alcanzar esta condición» ${ }^{77}$. Según Woolf, cuando no hay mezcla «el intelecto parece predominar y las demás facultades de la mente se endurecen y se vuelven estériles. Me consolé, sin embargo, pensando que quizá estemos en una fase pasajera (...) Es funesto para todo aquel que escribe pensar en su sexo. Es funesto ser un hombre o una mujer a secas (...) Por funesto entiendo mortal; porque cuanto se escribe con esta parcialidad consciente está condenado a morir (...) no puede crecer en la mente de los demás. Alguna clase de colaboración debe operarse para que el arte de la creación pueda realizarse (...) Es necesario que

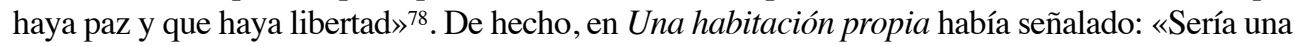
lástima terrible que las mujeres escribieran como los hombres, o vivieran como los hombres, o se parecieran físicamente a los hombres, porque dos sexos son ya pocos, dada la vastedad y variedad del mundo; ¿cómo nos las arreglaríamos, pues, con uno solo? ¿No debería la educación buscar y fortalecer más bien las diferencias que no los puntos de semejanza? Porque ya nos parecemos demasiado, y si un explorador volviera con la noticia de otros sexos atisbando por entre las ramas de otros árboles bajo otros cielos, nada podría ser más útil a la Humanidad»79.

En el escrito breve de 1940, Pensamientos de paz en un ataque aéreo, Woolf se refería a la lucha sin armas de fuego: «podemos luchar con la mente. Podemos inventar ideas que ayudarán al joven inglés que está luchando en el cielo a derrotar al enemigo» ${ }^{80}$. Y ante la tentación derrotista que «enfría el pensamiento y fomenta la irresponsabilidad», opone: «"No cesaré en la lucha mental", escribió Blake. La lucha mental significa pensar a contracorriente» ${ }^{81}$. Cuando el enemigo es un gusano bien interno, no es suficiente la independencia económica

73 Ibíd.

74 Ibíd.

75 Ibíd.

76 Op.cit., p. 126.

77 Op.cit., pp. 133-134.

78 Op. cit., pp. 140-141.

79 Op. cit., p. 120. En este sentido, cabe trazar un diálogo entre la posición de Woolf de ruptura de roles y de imposiciones, experimentación, provisionalidad, no-intervención, y la perspectiva del Übermench en Nietzsche. Sobre esta figura, véase el excelente capítulo de Diego Sánchez Meca: «Figuras del ultrahombre (Übermensch) nietzscheano», en Conill-Sancho, J., y Sánchez Meca, D., Guía Comares de Nietzsche, Granada, Comares, 2014. De hecho, «el Übermensch es el individuo capaz de pasar por muchos ideales, vivir caracteres y personajes diferentes, ver a través de cien ojos» (op. cit., p. 219).

80 Woolf, V., Pensamientos de paz en un ataque aéreo. Ed. Cit., p. 30.

81 Op.cit., p. 31. 
ni la educación para la paz. Ese gusano tiene además, aspectos diversos, como por ejemplo el «Ángel de la casa»: «Quizá no sepan qué quiero decir con el Ángel de la Casa. La describiré con la mayor brevedad posible. Era sumamente comprensiva. Era de lo más encantadora. Era inmensamente generosa. Destacaba en las difíciles artes de la vida familiar. Se sacrificaba día a día (...) en resumen, era tan íntegra que nunca se mostraba testaruda ni caprichosa, sino que prefería simpatizar siempre con las mentes y deseos de otros. Por encima de todo -necesito decirlo- era pura» ${ }^{82}$. La sombra de este Ángel -similar a un sacerdote interno que reaparece una y otra vez para indicarles a las mujeres que se comporten, que sean como se espera- ha de ser combatida: «Hice todo lo posible para matarla (...). Si yo no la hubiera matado, ella me habría matado a mí» ${ }^{83}$. El Ángel de la Casa impide a cada mujer ser ella misma, le impone una vida y una conciencia. Pero ¿qué significa ser ella misma? ¿Qué es una mujer? La respuesta de Woolf se desmarca de los esencialismos: «Les aseguro que no lo sé. No creo que ustedes lo sepan. No creo que nadie pueda saber hasta que se haya expresado en todas las artes y profesiones abiertas a la destreza humana» ${ }^{84}$. Para ser, por ejemplo, novelista es necesario «ser tan inconsciente como sea posible (...) inducirse a sí mismo un estado de aletargamiento eterno (...) Este estado es el mismo tanto para hombres como para mujeres» ${ }^{85}$. Sin embargo, la imaginación de una mujer impacta de inmediato contra algo que la sumerge en un estado de angustia y tribulación: «para no entrar en detalles, había pensado en algo, algo sobre el cuerpo, sobre las pasiones que ella, en tanto que mujer, no debía decir (...) La conciencia de lo que los hombres dirán de una mujer que habla con franqueza sobre sus pasiones la había arrancado de ese estado de inconsciencia propio del artista. No podía escribir más» ${ }^{86}$. Las mujeres están «impedidas por el convencionalismo extremo del otro sexo» ${ }^{87}$. Los hombres condenan la libertad, que ellos sí se toman, en las mujeres. Woolf afirma que ha logrado matar al Ángel, pero reconoce que no ha resuelto la segunda cuestión: la autocensura sobre sus pasiones: «Dudo que ninguna mujer la haya resuelto ya» ${ }^{88}$. En este sentido, la genealogía y, en general, el proceso de liberación del que habla Nietzsche a través de figuras como el espíritu libre o el superhombre, adquiere -aplicando la perspectiva de género- unas connotaciones distintas: «ella tiene todavía muchos fantasmas con que lidiar, muchos prejuicios que superar (...) un fantasma al que matar, una roca que esquivar $(. . .)^{89}$. Es imprescindible «hablar de los fines (...) por los que estamos librando una batalla contra estos temibles obstáculos (...) Siempre deben ser cuestionados y examinados» ${ }^{90}$. La habitación propia, la libertad política, incluso la independencia económica, es sólo el principio ${ }^{91}$.

82 Profesiones para mujeres. Ed. Cit., p. 213.

83 Op.cit., p. 214.

84 Op.cit., p. 215.

85 Op.cit., p. 217.

86 Ibíd.

87 Ibíd.

88 Ibíd.

89 Op.cit., p. 218.

90 Op.cit., p. 219.

91 «La habitación (...) está vacía (...) ¿Cómo la piensan amueblar (...)? ¿Con quién la piensan compartir, y cuáles serán las condiciones? (...) Estas son preguntas de la mayor importancia (...) Por primera vez en la historia, ustedes pueden formularlas; por primera vez pueden decidir por ustedes mismas cuáles deberían ser las respuestas» (ibíd.). 